\title{
¿Qué es la innovación social?
}

\author{
Entrevista a Dmitri Domanski \\ Profesor e investigador en innovación social del Instituto de \\ investigación social Sozialforschungsstelle Dortmund \\ Universidad de Dortmund, Alemania
}

\author{
Por María López Orduz \\ Estudiante de Ciencia política y Sociología \\ (maria.1.orduz@gmail.com)
}

\begin{abstract}
María López Orduz (MLO): Profesor Domanski, por favor cuéntenos cuál es ese tema que el Instituto de investigación social de la Universidad de Dortmund ha estado trabajando.

Dmitri Domanski (DD): Desde hace cinco años el Instituto trabaja el tema de la innovación social como su tópico central, y es abordado desde distintos enfoques como el género, la diversidad, la educación, la sostenibilidad, la salud y todo lo relacionado con el ámbito laboral.
\end{abstract}

MLO: ¿En qué consiste esa innovación social de la que habla?
DD: La innovación tiene que ver con nuevas prácticas sociales, con nuevas formas de hacer las cosas. No son innovaciones tangibles como nuevos artefactos o tecnologías, he ahí la distinción con la innovación tecnológica. La innovación social son nuevas formas de hacer algo, entre personas y entre organizaciones, con el objetivo de mejorar relaciones y problemas existentes para que funcionen de una manera que no se haya planteado antes.

MLO: ¿Podría decirse que la innovación social es también un cambio en la forma de pensar, un cambio en los paradigmas? 


\section{"La innovación tiene que ver con nuevas prácticas sociales, con nuevas formas de hacer las cosas. No son innovaciones tangibles como nuevos artefactos o tecnologías, (...) son nuevas formas de hacer algo, entre personas y entre organizaciones, con el objetivo de mejorar relaciones y problemas existentes para que funcionen de una manera que no se haya planteado antes"}

DD: Claro, las innovaciones siempre tienen que ver con eso. En ocasiones, las innovaciones son incrementales porque provienen de algo que ya existe pero que se mejora, no siempre resultan de algo radicalmente nuevo o nunca antes hecho. Ahora bien, éstas difícilmente se logran cuando no hay un cambio, cuando no se eliminan las barreras mentales. Los prejuicios obstaculizan la introducción e implementación de las soluciones, por lo que se puede decir que nosotros mismos podemos ser barreras para la innovación social.

MLO: ¿Por qué el Instituto tomó la decisión de tomar la innovación social como su tema central?
DD: Por varias razones. En primer lugar, mis colegas comprendieron que en medio de la diversidad de temas que estudian había algo en común, es decir, la creación, la introducción, la implementación y la difusión de nuevas prácticas sociales. Entonces dijimos, bueno si trabajamos esto con mucha experticia y desde hace tantos años ¿por qué no lo unimos dentro de un solo concepto?

En segundo lugar, porque nos dimos cuenta de que estamos viviendo en una época en la que el concepto o paradigma de innovación social ha cambiado sustancialmente. La innovación es ahora mucho más participativa e interactiva, es 
mucho menos lineal, se trata de redes y de sistemas de innovación. Y es ahí donde nosotros vemos la innovación social, pues esta muchas veces se logra a través de la participación de la gente de muy diferente posición. Esa es la razón principal del Instituto: la participación no solo de la gente de las comunidades, sino también de los científicos e investigadores de otros institutos, entre otros. En éste producimos investigaciones activas y participativas, $\mathrm{y}$ en ese sentido nuestra decisión de cambiar el tema fue bastante estratégica pues también somos innovadores.

MLO: En este momento ASHOKA está tomando liderazgo en el tema de la innovación social ¿tiene el Instituto una línea similar o tienen miradas distintas?

DD: No es lo mismo. Ellos son un representante de la sociedad civil bastante importante, no son un organismo científico que haga un trabajo académico. $\mathrm{Su}$ visión es exclusiva y la valoro, pero el emprendimiento social -que es en lo que ASHOKA se enfoca- es mucho más que eso. Nuestra visión es más amplia, el emprendimiento es solo una parte de eso. Lo que queremos es ver muy bien el rol de cada sector de la sociedad en términos de innovación social. Ellos se enfocan en emprendedores, nosotros queremos tener en cuenta al gobierno, a los organismos internacionales, a las universidades y a las empresas también. Su trabajo es concreto y exitoso pero es distinto.

MLO: ¿Cuál cree usted que debe ser el rol del gobierno en los procesos de innovación social?

DD: Es una muy buena pregunta que se discute mucho. De hecho, tiene varias discusiones ideológicas porque existe la escuela anglosajona de innovación social que le otorga poca responsabilidad a los gobiernos afirmando que es el tercer sector el que debe trabajar en este tema, mientras que en Europa central y oriental tenemos otra visión, pues no creemos pertinente la reducción del Estado. No creo que un Estado pequeño o reducido sea la solución. Lo que nosotros pensamos es que la innovación debe darse entre la sociedad civil y las empresas pero también debe estar presente el gobierno. Éste tiene mucha responsabilidad que asumir sin pensar en un rol asistencialista (como sucede en Latinoamérica), el gobierno debe apoyar con recursos concursables, sin fraude o corrupción porque cuando hay competencia se obtienen propuestas de mejor calidad. También puede aportar con centros donde 
la gente se eduque acerca de cómo generar e implementar innovaciones, como lo hacemos en el Instituto. Los centros educativos para la comunidad son solo un ejemplo de lo que el gobierno podría hacer pues tiene los recursos para empoderar y replicar la innovación social.

MLO: ¿Cree usted que existen cualidades o aptitudes que debe tener el innovador social?

DD: Realmente no he investigado acerca de ese tema, pero lo que sí puedo decir es que esa pregunta surge del enfoque estadounidense del emprendimiento social-lo cual es distinto a la innovación. Ellos tienen revistas poco académicas que se la pasan publicando artículos sobre el “innovador" y el top 5 de las actitudes necesarias. El enfoque norteamericano es muy psicológico, por ello la importancia del individuo. Pienso que esa mirada hay que analizarla muy bien.

Nosotros en Dortmund tenemos un enfoque distinto, nosotros hablamos de redes de innovación y de sistemas más que de individuos pues solos podemos lograr realmente muy poco. La mirada estadounidense quiere mostrar o contar la historia de héroes que salvan el mundo, pero la innovación social no se trata de cosas espontáneas o que surgen de repente como en las películas de Hollywood. Yo creo que la innovación requiere trabajo duro y tiempo de planificación que puede cambiar cosas a pequeña y a gran escala.

Ahora bien, para responderte diría que es muy importante tener una consciencia de trabajo en redes, si hay liderazgo en un grupo está bien pero es importante que este no opaque al colectivo sino que lo impulse y empodere. 
